\title{
Variant ABeta2M amyloidosis
}

INSERM

\section{Source}

INSERM. (1999). Orphanet: an online rare disease and orphan drug data base. Variant ABeta2M amyloidosis. ORPHA:314652

\#946;2M) leading to progressive gastrointestinal dysfunction, Sjögren syndrome (see this term) and autonomic neuropathy. 